\title{
SYNTHESIS AND CHARACTERIZATION OF HYDROXYAPTITE-
}

\section{POLYCARPOLACTON NANOCOMPOSITES USING NOVEL IN-SITU}

\section{SOL-GEL METHOD}

\section{B. Bhatkar ${ }^{1}$, V. G. Thakare ${ }^{1}$, N. V. Bhatkar ${ }^{2}$ and S. K. Omanwar ${ }^{3}$}

1. Department of Physics, SSESA's Science College, Nagpur (MS), India

2. Department of Zoology, Shri Shivaji College, Akot (MS), 444101 India

3. Department of Physics, SGB Amravati University, Amravati (MS), India E-mail: vaishalithakre1986@yahoo.com; bhatkar_vinod@yahoo.com Abstract

Hydroxyapatite (HA) is most substantial mineral constituent of bone which has biocompatibility and bioactivity properties. Nevertheless its mechanical properties are not appropriate for a bone substitution. Therefore, composites that consist of HA and biodegradable polymer are usually prepared to generate bone scaffolds. In the present work polycarpolactone (PCL) was employed as a matrix and Hydroxyapatite nanorods were used as reinforcement element of the composites. HA/PCL nonocomposites were synthesized by a new in-situ sol-gel process using low cost chemicals. Chemical and physical characteristics of nanocomposites were studied by $\mathrm{x}$-ray diffraction (XRD), Field effect scanning microscopy (FE-SEM) analyses. XRD analysis revealed that pure hydroxyapatite with no undesirable compound phases was formed with in nanocomposites. FE-SEM images showed dispersion of HA nanorods in PCL matrix.

Keywords: HA-PCL composites, nanocomposites, sol-Gel method.

\section{Introduction}

Interest in tissue engineering has grown over the last decade since it offers an alternative approach with great potential for reconstruction or replacement of damaged bone tissues [1]. Hydroxyapatite (HA) is chemically similar to the inorganic component of with general formula $\mathrm{Ca}_{10}(\mathrm{OH})_{2}(\mathrm{PO} 4)_{6}$. HA particles on nanometric scale (nHA) have been proved to be an osteoconductive material that also chemically binds to enamel and dentine [2]. Hydroxyapatite (HA) ceramics have been recognized as substitute materials for bone and teeth in orthopedic and dentistry field due to their chemical and biological similarity to human hard tissue [3]. More over HA has been recognized as a bioactive material having the direct bonding capability to the surrounding tissues therefore it has an excellent biocompatibility with human teeth and bone, making 
it very attractive for biomedical applications [4-7]. The greatest potential for bone substitution is shown by materials based on hydroxyapatite (HA), which can develop tight bonding with bone tissue, exhibits osteoconductive behavior, is stable toward bioresorption, and has no adverse effects on the human organism [8-9]. Polycaprolactone (PCL) is a synthetic biodegradable polymer that has been use for as bone graft substitutes. Polycaprolactone (PCL) is well known for biocompatible and biodegradable polymer and can be easily formed into thin layer with higher

mechanical properties. Because of those properties, PCL is highly considered for soft and hard tissue engineering fields [10-11]. Therefore, the idea of combining bioactive ceramics and degradable polymers to produce scaffolds with high porosity [12]. It is therefore to focus on, synthesis of HA/PCL nanocomposites scaffolds. HA/PCL nanocomposites characterization including phase determination, surface morphology, and analysis of particle size is presented in this paper.

\section{Experimental}

$\mathrm{HA} / \mathrm{PCL}$ nanocomposites scaffolds were prepared at $40^{\circ} \mathrm{C}$ from $\mathrm{Ca}\left(\mathrm{NO}_{3}\right)_{3}$ and $\left(\mathrm{NH}_{4}\right)_{2} \mathrm{HPO}_{4}$ as $\mathrm{Ca}$ and $\mathrm{P}$ precursors respectively. Acetone was used as a solvent and PCL was used as a nano-composites matrix. The procedure consists of two steps. The first step involves the addition of $4 \mathrm{gr}$ PCL add to 40cc acetone under the vigorous mixing condition of 2 hrs using magnetic stirrer. Then 2.3gr $\mathrm{Ca}\left(\mathrm{NO}_{3}\right)_{3}$ was added to the solution and mixed for $5 \mathrm{hrs}$ in a separate preparation, 0.79gr $\left(\mathrm{NH}_{4}\right)_{2} \mathrm{HPO}_{4}$ was added to $5 \mathrm{cc}$ acetone and vigorously mixed. Afterwards this solution was added to the PCL solution drop by drop. Ammonia was added to control the $\mathrm{P}_{\mathrm{H}}$ value around 10 . This final solution was stirred vigorously for $24 \mathrm{hrs}$. In second step, the scaffold was prepared by salt leaching method using sodium chloride crystal as porogens homogenously mixed with $\mathrm{HA} / \mathrm{PCL}$ solution at a weight ratio of approximately $9 / 1$ ( $\mathrm{NaCl} / \mathrm{PCL})$, at which point the composites solution 
become viscous. The mixture was poured into cylindrical mold and dried for $24 \mathrm{hrs}$ at room temperature. Finally daily rinsing in double distilled water for five days removed all $\mathrm{NaCl}$ as well as extra ions formed during reaction. The water was changed every $12 \mathrm{hrs}$.

\section{Result and Discussion}

A sol-gel method was used to synthesis HA/PCL nanocomposites materials with ceramic phase nanorods dispersed in a polymeric matrix. The morphology HA/PCL nanocomposites were studied using FE-SEM (HITACHI S-4800) at an operating voltage of $15 \mathrm{kV}$. FE-SEM image of nano-composites washed with double distilled water several times is shown in fig. 1 . It can be seen that in fig. $1 \mathrm{~b}$ that dispersion of nanorods in PCL matrix with suitable interaction was obtained. It has been reported that HA clustering happens in polymeric matrix due to hydrophilicity of HA and hydrophobicity of PCL [13] In order to increase the porosity size of HA/PCL nanocomposites a solvent casting/particulate leaching method was employed to prepare corresponding scaffolds.

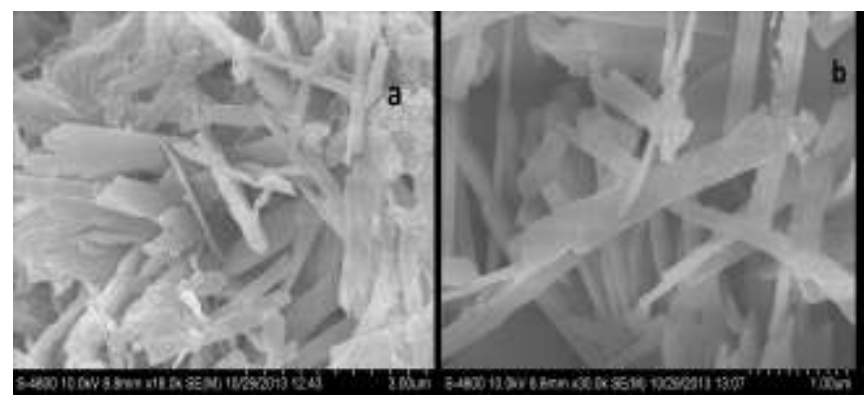

Fig. 1 FE-SEM micrographs of HA/PCL

nanocomposites synthesis by an in situ Sol-gel process HA/PCL nanocomposites with nonoporous structure containing HA nanorods with diameter $53 \mathrm{~nm}$ is synthesized. 


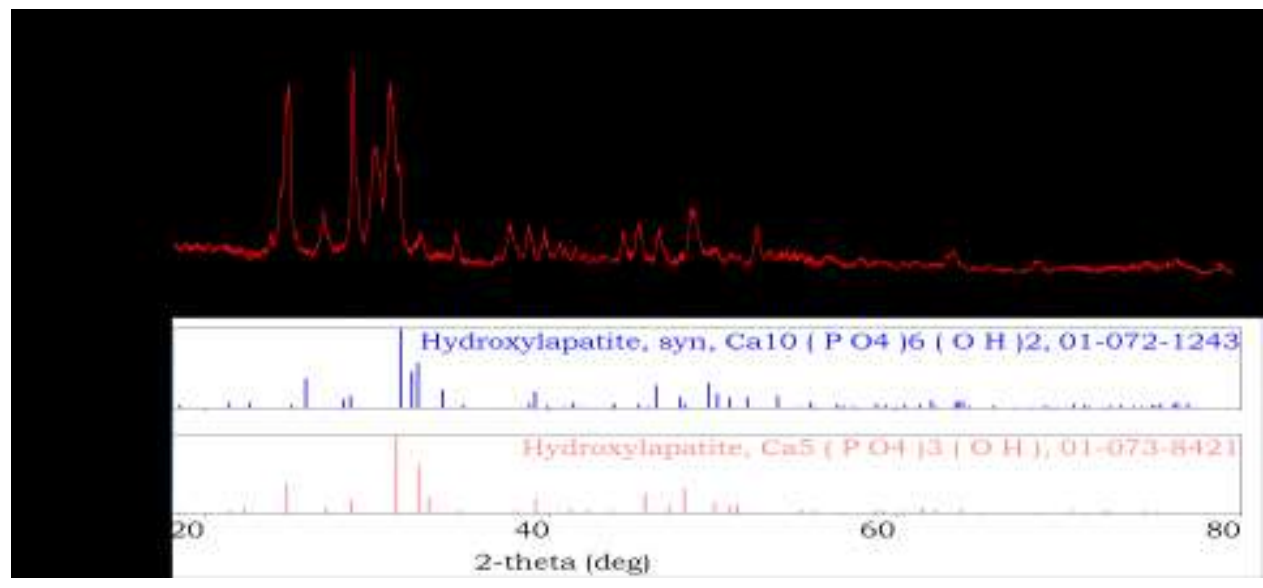

Fig. 2: XRD of HA/PCL

nanocoposites prepared by in Sol-gel synthesis $\left(\bullet=\mathrm{PCL},{ }^{*}=\mathrm{HA}\right)$ formation of HA compound from their corresponding reflections Phase composition of synthesized PCL/HA composites was studied using X- Ray Diffractometer (XRD, miniflex Rigaku) at 30kVand 15mA utilizing CuKa radiation. The range of $2 \theta$ angles was from $20^{\circ}$ to $80^{\circ}$, at a step size of $0.02^{\circ}$ and step time of $1 \mathrm{~s}$. The structural analysis of sample was done by the powder X-ray diffraction. The mean crystalline size (D) of the sample was calculated from the XRD line broadening measurement using the Scherrer equation [12].

Where $\lambda$ is the wavelength $(\mathrm{CuKa}), \mathrm{B}$ is the full width at the half maximum of HA $(211) 2 \Theta=31.373^{\circ}$ reflection which has the highest intensity among HA peaks and $\Theta$ is the diffraction angle. Fig.2: XRD of HA/PCL nanocoposites, PCL is semi-crystalline polymer which can detected XRD peaks as labeled by $\bullet$ mark [2] and HA specific peaks were labeled by * mark and were matched with database in ICDD file number 01-072-1243 and 01-073-8221. It can be observed that HA peaks were broad; accordingly, it could be inferred that they have small particle sizes and low crystallinity. This can be related to the synthesis process at a low temperature. 


\section{Conclusions}

HA/PCL nanocomposites and scaffolds containing HA nanorods was successfully synthesized by in situ sol-gel process. Starting with low cost precursors and solvent such as calcium nitrate, di-ammonium hydrogen orthophosphate and acetone respectively reduced total cost of production. FE-SEM images shows that the HA nanorods dispersed in PCL Polymeric matrix. XRD analysis confirmed that the formation of hydroxyapatite.

\section{References}

S. Lohfeld, S. Cahill1, V. Barron, P. Mchugh, L. Dürselen, L. Kreja, C. Bausewein, and A. Ignatius. (2012). "Fabrication, mechanical and in vivo performanc of polycaprolactone/tricalciumphosphate composite scaffolds" Acta Biomaterialia, 8,3446-3456.

A. Rezaei, and M. R. Mohammadi. (2012) . "Development of Hydroxyapatite nanorods Polycaprolactone Composites andScaffolds Derived from a Novel In-Situ Sol-Gel Process" Tissue Engineering and

Regenerative Medicine, 9 ,295-303.

E. B. Yarosh, B. A. Dmitrevskii, V. P. Naryzhnyi, and S. K. Tsvetkov. (2001). "Some Characteristics of Synthetic Hydroxyapatite" Russian Journal of Applied Chemistry, 74,1058-1060.

R. Quan, D. Yang, X. Wu, H. Wang, X. Miao, and W. Li. (2008). "In vitro and in vivo biocompatibility of graded hydroxyapatite-zirconia composite bioceramic" Journal Mater Science: Mater Med, 19,183187.

E. Bouyer, F. Gitzhofer, and M. I. Boulos. (2000). "Morphological study of hydroxyapatite nanocrystal suspension" journal of materials science: materials in medicine, $11,523-531$. 
A. Jillavenkatesa, and R. A. condra. (1998) . "Sol-gel processing of hydroxyapatite" Journal of Materials Science, 33, 4111 - 4119.

V. V. Silva, and R. Z. Domingues. (1997). "Hydroxyapatite-zirconia composites prepared by precipitation method Journal of materials science: materials in medicine, 8 , 907-910.

V. P. Orlovskii, V. S. Komlev, and S. M. Barinov. (2002) "Hydroxyapatite and Hydroxyapatite-Based Ceramics" Inorganic Materials, 38 973984.

S. S. Zargarian, and V. H. Asl. (2010). "A Nanofibrous Composite Scaffold of PCL/Hydroxyapatite-chitosan/PVA Prepared by Electrospinning" Iranian Polymer Journal, 19 , 457-468.

M. Kim, I. Park, Y. H. Kim, H. Y. Song, Y.K. Min, and B. T. Lee. (2011). "Fabrication and Characterization of Strengthened BCP Scaffold Through Infiltration of PCL in the Frame" Bioceramics Development and Applications, $1,1-4$.

J. Y. Liu, L. Reni, Q. Wei, J. L. Wu1, S. Liu, Y. J. Wang, and G. Y. Li, (2011). "Fabrication and characterization of polycaprolactone/calcium sulfate whisker composites" eXPRESS Polymer Letters, 5 , 742-752.

A.R. Rezaei, and M.R. Mohammadi, "Synthesis of slightly carbonatedhydroxyapatite nano-rods and polycaprolactone composites by a wet chemical route" Proceedings of the 4th International Conference on Nanostructures (ICNS4) (2012) 12-14 Kish Island Iran.

I. Mobasherpour, M. S. Heshajin, and A. Kazemzade. (2007). "Synthesis of nanocrystalline hydroxyapatite by coprcipritation method" Journal of alloy comp. 430,330 . 